\title{
Obesity Is an Independent Determinant of Ischemia-Modified Albumin ${ }^{1}$
}

\author{
İdris Mehmetoğlu ${ }^{a}$ Sevil Kurban ${ }^{a}$ Fatma Hümeyra Yerlikaya ${ }^{a}$ Hakkı Polat $^{b}$ \\ ${ }^{a}$ Department of Biochemistry, ${ }^{b}$ Department of Internal Medicine, Meram Faculty of Medicine, \\ Necmettin Erbakan University, Konya, Turkey
}

\section{Key Words}

Obesity $\cdot$ Ischemia-modified albumin $\cdot$ High-sensitivity C-reactive protein $\cdot$ Total antioxidant status $\cdot$ Total oxidant status

\begin{abstract}
Objective: We have measured ischemia-modified albumin (IMA), total antioxidant status (TAS), total oxidant status (TOS) and high-sensitivity C-reactive protein (hsCRP) levels in obese and normal-weight subjects to investigate if IMA can be used as a biomarker of oxidative stress and inflammation and if IMA was an independent determinant of obesity or not. Methods: The study was performed on 92 obese subjects ( 20 male, 72 female) aged $38 \pm 11$ years and 78 normal-weight controls (19 male, 59 female) aged $37 \pm 11$ years. Serum lipids, IMA, TAS, TOS, and hsCRP levels of the subjects were measured. Results: IMA $(p<0.05)$, TOS ( $p<$ $0.001)$, and hsCRP $(p<0.001)$ levels of the obese subjects were significantly higher, whereas TAS levels were significantly lower $(p<0.05)$ than those of the controls after adjustment for age and gender. In the linear regression analysis, waist circumference $\left(r^{2}=0.139, p<0.01\right)$, BMI $\left(r^{2}=0.136, p<0.01\right)$ and insulin $\left(r^{2}=0.120, p<0.05\right)$ were shown to be significant independent determinants of IMA levels. Conclusions: We have found that oxidative stress and inflammation were increased and antioxidative defense was decreased, which resulted in increased levels of IMA, a biomarker of ischemia, in obese subjects. Also, obesity and insulin were found to be independent determinants of IMA. Thus, obese subjects are under high risk of ischemia, and IMA may be used as a biomarker of oxidative stress and ischemia. Further larger investigations are needed to confirm this opinion.
\end{abstract}

1 The study has been presented as a poster at the First European Joint Congress of EFCC and UEMS, October 13-16, 2010, Lisbon, Portugal. 


\section{Introduction}

Obesity is excessive body fat accumulation that presents a risk to health, leading to reduced life expectancy [1, 2]. In addition to serving as a storage depot for lipid energy, adipose tissue is now recognized to be an active participant in energy homeostasis and physiological functions such as immunity and inflammation. Adipose tissue is known to express and secrete a variety of products known as 'adipokines', including leptin, adiponectin and resistin, as well as cytokines and chemokines, such as tumor necrosis factoralpha and interleukin- 6 . The release of adipokines leads to a chronic subinflammatory state that could play a central role in the development of insulin resistance and type 2 diabetes mellitus (DM) and may also be responsible for the increased risk of cardiovascular disease (CVD) associated with obesity [3]. Indeed, obese individuals have been reported to experience substantially elevated morbidity and mortality from type 2 DM [2], cancers [4], and nearly all forms of CVD [5].

Ischemia, hypoxia, acidosis, and free radical formation can alter the ability of the amino terminal end (N-terminal) of the albumin molecule to bind transitional metals such as cobalt, copper, and nickel [6-8]. Many studies have evaluated the clinical utility of ischemiamodified albumin (IMA) in patients with suspected acute coronary syndromes [8] and myocardial ischemia [9]. Also, IMA was reported to increase in diseases related to obesity such as metabolic syndrome [10], hypercholesterolemia [11], and type 2 DM [12].

Oxidative stress can occur due to overproduction of oxidants, decrease in antioxidant defense, or a combination of these factors. The natural antioxidant system consists of antioxidant enzymes and numerous antioxidant compounds and protects the functional and structural molecules against the reactive oxygen species (ROS). The generation of ROS can at least transiently modify the N-terminal region of albumin to yield increased levels of IMA [7]. Total antioxidant status (TAS) measurement is a simple indicator of the activity of all antioxidants while total oxidant status (TOS) is an indicator of total oxidative stress [13,14].

Recently, it has been shown that obesity reduces the capacity of albumin to bind cobalt, resulting in higher IMA levels $[15,16]$. However, there is no study investigating the association between oxidative stress and inflammation biomarkers such as TAS, TOS, and highsensitivity C-reactive protein (hsCRP) in obese people.

Therefore, we have investigated how oxidative stress and inflammation affect the formation of the novel diagnostic marker IMA by measuring serum IMA, TAS, TOS, and hsCRP levels and correlations between them in obese subjects. In addition, we tried to find out whether or not IMA was an independent determinant of obesity. Thus we have aimed to explore the molecular basis and complications of obesity and to contribute to prevention and treatment strategies of obesity.

\section{Participants and Methods}

\section{Subjects}

92 obese subjects ( 20 male, 72 female) aged 20-65 years (mean $38 \pm 11$ years) and 78 normal-weight controls (19 male, 59 female) aged 19-68 years (mean $37 \pm 11$ years) were enrolled in the study. Anthropometric and clinical characteristics of the groups are given in table 1. Potential subjects were excluded from participation in the study if any of the following conditions were noted: DM, chronic liver disease, hypertension, cancer, inflammatory diseases, serious dyslipidemia, or a history of CVD. Systolic blood pressure greater than $140 \mathrm{~mm} \mathrm{Hg}$ and diastolic blood pressure greater than $90 \mathrm{~mm} \mathrm{Hg}$ were defined as criteria of hypertension [17]. The controls were age-matched normal-weight people with a BMI between 18.5 and $24.9 \mathrm{~kg} / \mathrm{m}^{2}$ and with no complaints or pathological laboratory findings. 
Table 1. Anthropometric and clinical characteristic of the participants grouped according to BMI

\begin{tabular}{|c|c|c|c|}
\hline & $\begin{array}{l}\text { Control group } \\
(n=78)\end{array}$ & $\begin{array}{l}\text { Obese group } \\
(n=92)\end{array}$ & $\mathrm{p}$ value ${ }^{\mathrm{b}}$ \\
\hline Gender (M/F) & $19 / 59$ & $20 / 72$ & 0.686 \\
\hline Age, years & $37 \pm 11$ & $38 \pm 11$ & 0.455 \\
\hline BMI, $\mathrm{kg} / \mathrm{m}^{2}$ & $21.1 \pm 2.6$ & $42.4 \pm 6.6$ & $<0.001$ \\
\hline \multirow[t]{2}{*}{ Waist circumference, $\mathrm{cm}$} & M: $84.4 \pm 5.3$ & M: $119.0 \pm 11.3$ & $<0.001$ \\
\hline & $\mathrm{F}: 71.0 \pm 7.4$ & F: $118.9 \pm 9.9$ & $<0.001$ \\
\hline Waist-to-hip ratio & $0.78 \pm 0.05$ & $0.87 \pm 0.07$ & $<0.001$ \\
\hline Systolic BP, mm Hg & $115.9 \pm 1.2$ & $133.7 \pm 2.5$ & $<0.001$ \\
\hline Diastolic BP, mm Hg & $69.6 \pm 1.0$ & $84.6 \pm 1.1$ & $<0.001$ \\
\hline Glucose, mg/dl & $83.9 \pm 8.2$ & $96.2 \pm 16.5$ & $<0.001$ \\
\hline Insulin, $\mu \mathrm{U} / \mathrm{ml}$ & $4.8 \pm 1.8$ & $16.7 \pm 9.5$ & $<0.001$ \\
\hline HOMA-IR & $1.04 \pm 0.4$ & $3.98 \pm 2.4$ & $<0.001$ \\
\hline $\mathrm{TC}, \mathrm{mg} / \mathrm{dl}$ & $181 \pm 37$ & $194 \pm 34$ & 0.020 \\
\hline $\mathrm{TG}, \mathrm{mg} / \mathrm{dl}$ & $77.7 \pm 38$ & $145.0 \pm 76$ & $<0.001$ \\
\hline $\mathrm{HDL}-\mathrm{C}, \mathrm{mg} / \mathrm{dl}$ & $50.5 \pm 14$ & $41.8 \pm 12$ & $<0.001$ \\
\hline LDL-C, mg/dl & $115 \pm 34$ & $123 \pm 35$ & 0.128 \\
\hline
\end{tabular}

$\mathrm{BP}=$ Blood pressure; HOMA-IR = homeostasis model assessment; $\mathrm{TG}=$ triglyceride; $\mathrm{TC} 0=$ total cholesterol; HDL-C = high-density lipoprotein cholesterol; LDL-C = low-density lipoprotein cholesterol.

${ }^{a}$ Obesity occurrence, according to BMI values $\geq 30 \mathrm{~kg} / \mathrm{m}^{2}$ and normal weight people occurrence, according to BMI values between 18.5 to $24.9 \mathrm{~kg} / \mathrm{m}^{2}$. Data are presented as mean values \pm SD (except gender).

${ }^{\mathrm{b}} \mathrm{P}$ values derived from independent samples t-test for normally distributed variables, Mann-Whitney $\mathrm{U}$ test for non-normally distributed variables and $\chi^{2}$ test for categorical variables.

BMI was measured in all participants as obesity criterion. BMI was obtained by dividing a person's weight (in $\mathrm{kg}$ ) by the square of his or her height (in $\mathrm{m}$ ). Subjects were required to wear only light clothes and stand straight, barefoot, and at ease when being measured. Both the scales and stadiometer were calibrated before use. Subjects with a BMI between 25 and $29.9 \mathrm{~kg} / \mathrm{m}^{2}$ were considered as overweight and those with a BMI $\geq 30 \mathrm{~kg} / \mathrm{m}^{2}$ were considered as obese [1]. Waist circumference was used as a central adiposity indicator, considering values higher than 80 and $94 \mathrm{~cm}$ for woman and man, respectively [18]. Participants' waist circumferences were measured with a soft tape midway between the lowest rib and the iliac crest. The hip circumference was measured at the widest part of the gluteal region.

The study protocol was approved by the Ethics Committee of Meram Medical School, University of Selcuk, Konya, Turkey. All subjects were informed of the details of the study, and written consent of each patient was received.

Venous blood samples were drawn after an overnight fasting state. Blood samples were processed for routine analysis, and sera were freezed at $-80^{\circ} \mathrm{C}$ within $2 \mathrm{~h}$ of sample collection for later testing of IMA, TAS, and TOS. Blood lipids, hsCRP, and glucose levels were measured by routine methods on an autoanalyzer (Beckman Coulter, Fullerton, CA, USA), and insulin levels were determined by routine chemiluminescence method on an E170 analyzer (Roche Diagnostics, Rotkreuz, Switzerland) on the same day of sample collection. Homeostasis model assesment of insulin resistance (HOMA-IR) was used to detect the degree of insulin resistance and calculated by equations given by Mathews et al. [19].

\section{Measurement of IMA Levels}

IMA levels were measured by a colorimetric assay developed by Bar-Or etal. [9] based on measurement of unbound cobalt after incubation with patient serum. Increased amounts of IMA result in less cobalt binding and more residual unbound cobalt available for complex with a chromogen (dithiothreitol (DTT)), which can be measured photometrically. The procedure was as follows:

$50 \mu \mathrm{l}$ of $1 \%$ cobalt chloride was added to $200 \mathrm{ml}$ of serum, gently mixed, and incubated for $10 \mathrm{~min}$ to allow for adequate cobalt-albumin binding. $50 \mu \mathrm{l}$ of DTT, at a concentration of $1.5 \mathrm{mg} / \mathrm{ml}$, was added as a 
colorizing agent; the reaction was stopped 2 min later by adding $1.0 \mathrm{ml}$ of $0.9 \% \mathrm{NaCl}$. The colored product was measured at $470 \mathrm{~nm}$ and compared to a serum-cobalt blank without DTT; the results were reported in absorbance units (ABSU). The intra-assay and inter-assay coefficient of variance (CV) for IMA were calculated by repeating a patient sample in eight assays in duplicate and were found to be $6.5 \%$ and $8.7 \%$, respectively.

\section{Measurement of TAS}

TAS of sera was determined using a commercially available kit (Rel Assay Diagnostic, Lot: RL015, Gaziantep, Turkey) which was based on the bleaching of the characteristic color of a more stable 2,2'-azinobis (3-ethylbenz-thiazoline-6-sulfonic acid) (ABTS) radical cation by antioxidants [13]. The results were expressed in mmol Trolox equivalents/l. The intra-assay and inter-assay CVs for TAS were $1.3 \%$ and $1.5 \%$, respectively. The sensitivity of the assay was $0.04 \mathrm{mmol}$ Trolox equivalents/l.

\section{Measurement of TOS}

TOS of sera was determined using a commercially available kit (Rel Assay Diagnostic, Lot: RL015) which was based on oxidation of ferrous ion-0-dianisidine complex to ferric ion by oxidants present in the sample. The oxidation reaction is enhanced by glycerol molecules, which are abundantly present in the reaction medium. The ferric ion makes a colored complex with xylenol orange in an acidic medium. The color intensity, which can be measured spectrophotometrically, is related to the total amount of oxidant molecules present in the sample. The assay is calibrated with hydrogen peroxide $\left(\mathrm{H}_{2} \mathrm{O}_{2}\right)$ and the results are expressed in terms of $\mu \mathrm{mol} \mathrm{H}_{2} \mathrm{O}_{2}$ equivalents/l [14]. The intra-assay and inter-assay CVs for TOS were lower than $3 \%$. The sensitivity of the assay was $1.13 \mu \mathrm{mol} \mathrm{H}_{2} \mathrm{O}_{2}$ equivalents/l.

\section{Statistical Analysis}

All statistical analyses were performed using the Statistical Package for the Social Sciences (SPSS, Version 16.0, Chicago, IL, USA). The post-hoc power of the study was found to be 0.72 . The descriptive variables were defined as mean value \pm standard deviation (SD). The normality of the variables was evaluated using the one-sample Kolmogorov-Smirnov test. The normal distribution of variables (age, BMI, waist circumference, waist-to-hip ratio, systolic and diastolic blood pressure, glucose, HOMA-IR, total cholesterol (TC), high-density lipoprotein cholesterol (HDL-C) and low-density lipoprotein cholesterol (LDL-C)) were examined with Independent-Samples t test, and non-normally distributed variables (insulin and triglyceride (TG)) were examined by Mann-Whitney U test. Categorical variables were examined with $\chi^{2}$ test. We performed a univariate analysis of variance to compare age- and gender-adjusted levels of serum TAS, TOS, IMA, and hsCRP concentrations of normal-weight controls and obese subjects. The correlations between variables were done by Pearson's correlation test for normally distributed variables and by Spearman correlation analysis non-normally distributed variables. Then, we performed a linear regression analysis to examine the relative contribution of BMI, waist circumference, insulin, HOMA-IR, age, and gender to IMA. Differences were considered significant at a probability level of $\mathrm{p}<0.05$.

\section{Results}

The results are given in table 2. IMA $(\mathrm{p}<0.05)$, TOS $(\mathrm{p}<0.001)$ and hsCRP $(\mathrm{p}<0.001)$ levels of the obese subjects were significantly higher, whereas TAS levels of the obese subjects were significantly lower $(\mathrm{p}<0.05)$, than those of the controls after adjustment for age and gender. There were significant positive correlations between the following parameters of the obese subjects: IMA and BMI ( $r=0.250, p<0.05)$, IMA and waist circumference $(\mathrm{r}=0.347, \mathrm{p}<0.01)$, hsCRP and BMI ( $\mathrm{r}=0.416, \mathrm{p}<0.01)$, hsCRP and waist circumference $(r=0.290$, p < 0.01) (fig. 1), insulin and IMA ( $r=0.320$, p < 0.01), insulin and waist circumference $(r=0.425, p<0.01)$, HOMA-IR and IMA ( $r=0.262$, p < 0.05), HOMA-IR and waist circumference ( $r=0.455, \mathrm{p}<0.01$ ) (fig. 2), TG and BMI ( $r=0.207, \mathrm{p}<0.05)$, and TG and waist circumference $(r=0.278, p<0.01)$ (table 3). Also, BMI was positively correlated with glucose $(\mathrm{r}=0.245, \mathrm{p}<0.05)$, HOMA-IR ( $\mathrm{r}=0.313$, $\mathrm{p}<0.01)$, TC $(\mathrm{r}=0.277, \mathrm{p}<0.05)$, TG $(\mathrm{r}=0.352$, $\mathrm{p}<0.01)$, and LDL-C $(\mathrm{r}=0.365, \mathrm{p}<0.01)$ but negatively correlated with HDL-C $(\mathrm{r}=-0.408$, 
Mehmetoğlu et al.: Obesity Is an Independent Determinant of Ischemia-Modified

Table 2. Oxidative stress and inflammatory biomarkers of participants adjusted according to age and gender on univariate analysis ${ }^{a}$

\begin{tabular}{lccc}
\hline Parameters & $\begin{array}{l}\text { Control group } \\
(\mathrm{n}=78)\end{array}$ & $\begin{array}{l}\text { Obese group } \\
(\mathrm{n}=92)\end{array}$ & $\mathrm{p}$ value $^{\mathrm{b}}$ \\
\hline $\mathrm{IMA}, \mathrm{ABSU}$ & $0.73 \pm 0.19$ & $0.80 \pm 0.16$ & 0.036 \\
TAS, mmol Trolox equivalents/l & $2.67 \pm 0.40$ & $2.56 \pm 0.62$ & $<0.05$ \\
TOS, $\mu \mathrm{mol} \mathrm{H} \mathrm{O}_{2}$ equivalents/l & $16.37 \pm 10.37$ & $23.79 \pm 10.68$ & $<0.001$ \\
hSCRP, $\mathrm{mg} / \mathrm{l}$ & $4.85 \pm 3.71$ & $13.46 \pm 7.87$ & $<0.001$ \\
\hline
\end{tabular}

${ }^{\text {a }}$ Data are presented as mean values \pm SD.

${ }^{b} \mathrm{P}$ values derived from univariate analysis.

Fig. 1. Correlations between A hsCRP and BMI, B hsCRP and waist circumference, C IMA and BMI as well as D IMA and waist circumference of obese subjects.

Fig. 2. Correlations between A IMA and HOMA-IR, B IMA and insulin, C waist circumference and HOMA-IR as well as D waist circumference and insulin of obese subjects.
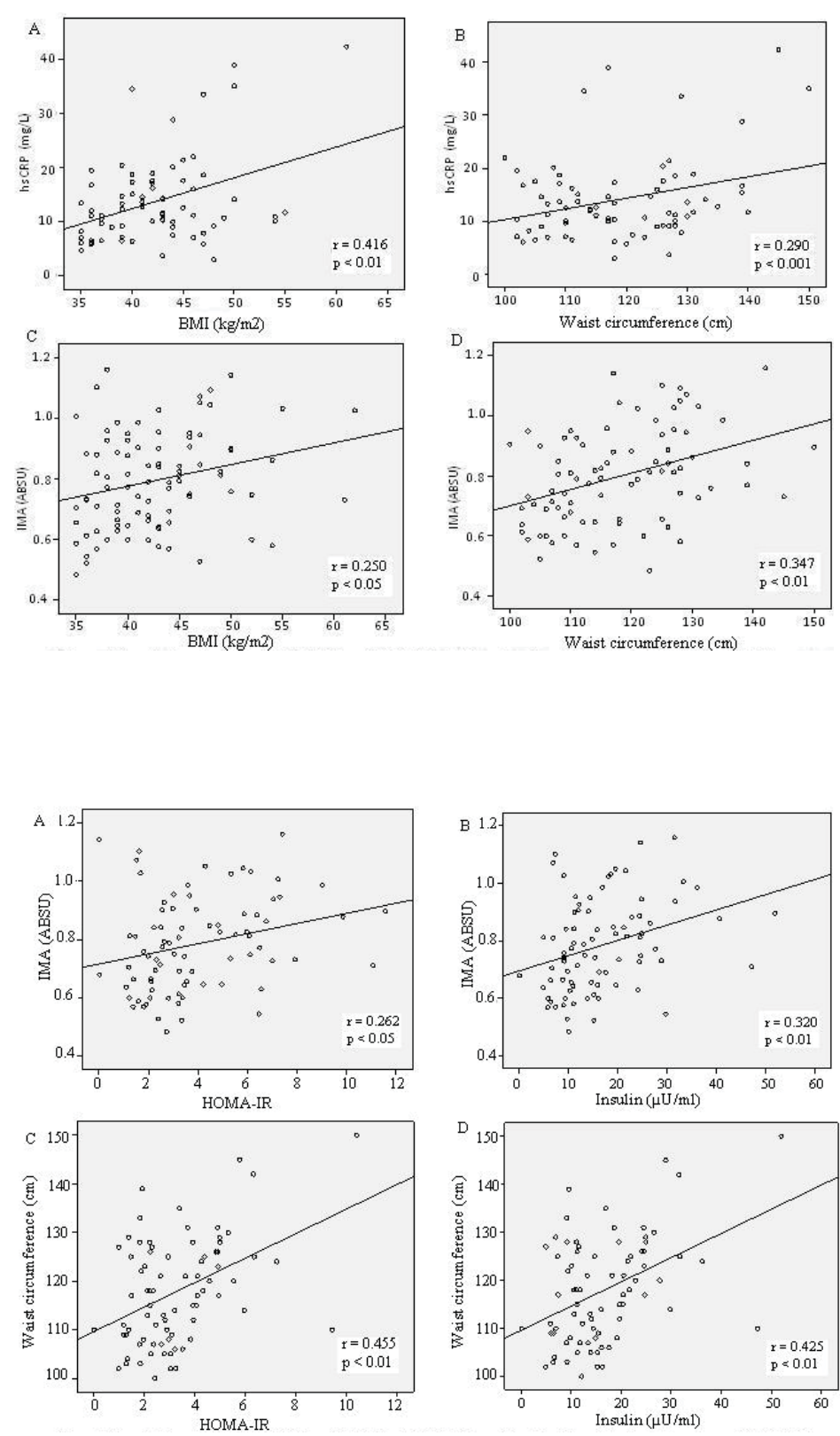
Table 3. Correlations of oxidative stress markers and anthropometric variables with lipid profile and hsCRP of the groups ${ }^{\mathrm{a}}$

\begin{tabular}{|c|c|c|c|c|c|}
\hline & IMA & TAS & TOS & BMI & Waist circumference \\
\hline \multicolumn{6}{|c|}{ Obese group $(n=92)$} \\
\hline $\mathrm{TC}$ & 0.039 & -0.076 & 0.163 & 0.029 & 0.068 \\
\hline $\mathrm{TG}$ & $0.386^{* *}$ & 0.142 & -0.044 & $0.207^{*}$ & $0.278^{* *}$ \\
\hline HDL-C & $-0.299^{*}$ & 0.048 & 0.125 & 0.079 & -0.123 \\
\hline LDL-C & -0.023 & 0.010 & 0.050 & -0.079 & 0.062 \\
\hline hsCRP & 0.056 & 0.095 & 0.073 & $0.416^{* *}$ & $0.290^{* *}$ \\
\hline Glucose & -0.084 & 0.229 & 0.049 & 0.121 & 0.180 \\
\hline Insulin & $0.320^{* *}$ & 0.112 & -0.131 & 0.092 & $0.425^{* *}$ \\
\hline HOMA-IR & $0.262^{*}$ & 0.179 & -0.099 & 0.116 & $0.455^{* *}$ \\
\hline IMA & 1 & 0.202 & -0.132 & $0.250^{*}$ & $0.347^{* *}$ \\
\hline \multicolumn{6}{|c|}{ Control group $(n=78)$} \\
\hline $\mathrm{TC}$ & 0.124 & -0.068 & 0.145 & $0.277^{*}$ & $0.445^{* *}$ \\
\hline TG & 0.059 & -0.135 & 0.266 & $0.352^{* *}$ & $0.546^{* *}$ \\
\hline HDL-C & -0.195 & -0.023 & -0.061 & $-0.408^{* *}$ & $-0.506^{* *}$ \\
\hline LDL-C & 0.206 & 0.041 & 0.231 & $0.365^{* *}$ & $0.447^{* *}$ \\
\hline hsCRP & 0.153 & 0.032 & 0.032 & 0.072 & 0.095 \\
\hline Glucose & 0.067 & -0.008 & -0.079 & $0.245^{*}$ & $0.263^{*}$ \\
\hline Insulin & 0.041 & 0.123 & 0.034 & 0.224 & 0.146 \\
\hline HOMA-IR & 0.057 & 0.178 & -0.024 & $0.313^{* *}$ & $0.250^{*}$ \\
\hline IMA & 1 & 0.061 & -0.289 & -0.039 & -0.029 \\
\hline
\end{tabular}

aThe correlations between variables were performed by Pearson's Correlation test for normal distribution and Spearman Correlation analysis was performed for non-normally distributed variables.

${ }^{*} \mathrm{p}<0.05$.

${ }^{* *} \mathrm{p}<0.01$.

$p<0.01)$. Waist circumference was positively correlated with glucose $(r=0.263, p<0.05)$, HOMA-IR ( $\mathrm{r}=0.250, \mathrm{p}<0.05)$, TC $(\mathrm{r}=0.445, \mathrm{p}<0.01)$, TG $(\mathrm{r}=0.546, \mathrm{p}<0.01)$, and LDL-C $(\mathrm{r}=0.447, \mathrm{p}<0.01)$ but negatively correlated with HDL-C $(\mathrm{r}=-0.506, \mathrm{p}<0.01)$ in the control group (table 3 ).

On the other hand, there were no correlations between oxidative stress biomarkers in the obese and controls (data not shown). In linear regression analysis, waist circumference $\left(r^{2}=0.139, p<0.01\right)$, BMI $\left(r^{2}=0.136, p<0.01\right)$ and insulin $\left(r^{2}=0.120, p<0.05\right)$ were significant independent determinants of IMA levels (table 4).

\section{Discussion}

Obese subjects have been reported to present a chronic inflammatory state in the adipose tissue that might have a strong relationship with onset and development of obesityrelated diseases $[2,3,20]$. In addition, adipose tissue of obese subjects is poorly oxygenated, and this hypoxia state is another potential risk factor for chronic inflammation in obesity [21].

Our results show that IMA levels of obese subjects were significantly higher than those of normal-weight controls. This finding is in agreement with the results of Piva et al. [15]. Therefore, it is obvious that obese subjects had a high risk of ischemia, a finding which is confirmed by positive correlations between IMA and BMI as well as between IMA and waist 
Table 4. Predictors of serum IMA

\begin{tabular}{|c|c|c|c|c|}
\hline & B & Standard error & $\mathrm{t}$ & $\mathrm{p}$ \\
\hline Constant & 0.210 & 0.230 & 0.917 & 0.363 \\
\hline Age & -0.003 & 0.002 & -1.614 & 0.111 \\
\hline Gender & 0.029 & 0.045 & 0.641 & 0.523 \\
\hline Waist circumference, $\mathrm{cm}$ & 0.005 & 0.002 & 0.350 & 0.003 \\
\hline Constant & 0.289 & 0.201 & 1.437 & 0.155 \\
\hline Age & -0.002 & 0.001 & -1.112 & 0.253 \\
\hline Gender & 0.058 & 0.040 & 1.433 & 0.156 \\
\hline BMI, $\mathrm{kg} / \mathrm{m}^{2}$ & 0.009 & 0.003 & 2.941 & 0.004 \\
\hline Constant & 0.557 & 0.158 & 3.516 & 0.001 \\
\hline Age & -0.001 & 0.002 & -0.312 & 0.756 \\
\hline Gender & 0.051 & 0.048 & 1.068 & 0.289 \\
\hline Insulin, $\mu \mathrm{U} / \mathrm{ml}$ & 0.004 & 0.002 & 2.081 & 0.041 \\
\hline
\end{tabular}

circumference in obese subjects. Also, we have found that BMI and waist circumference were independent determinants of serum IMA levels, a finding which supports the above suggestion.

Also, we could show a significant increase in serum hsCRP levels in obese subjects, which is an indicator of inflammation. This finding is in accordance with those of other investigators too $[22,23]$.

Although the underlying mechanism of increased IMA levels in obese subjects is not known, we believe that a generalized inflammation as evidenced by elevated levels of hsCRP and increased free radical injury as proven by elevated levels of TOS and reduced levels of TAS may lead to that situation, as it has been reported that IMA is produced under all conditions where potent producers of free radicals are available [9, 24]. Moreover, obesity is known to be a chronic inflammatory state which is a source of oxidative stress. This opinion is supported by our finding of a significant positive correlation between BMI and serum hsCRP as well as between waist circumference and hsCRP levels. These findings are in agreement with the findings of other investigators [20, 23-27]. In addition, it was shown that a moderate weight loss resulted in decreased circulating levels of hsCRP [28] which implies the presence of inflammation in obese subjects.

Our results showed that oxidative stress was significantly higher in obese subjects than in controls, which is in agreement with the results of other investigators $[5,29,30]$. Significantly positive correlations between IMA and waist circumference as well as between IMA and BMI as found in our study show that increased IMA levels are directly related to obesity.

We also found significantly positive correlations between waist circumference and insulin as well as between waist circumference and HOMA-IR. Moreover, there were significantly positive correlations between IMA and insulin as well as between IMA and HOMA-IR. In addition, we found that insulin was an independent determinant of IMA the underlying mechanism of which is not known and needs to be investigated.

On the other hand, significantly positive correlations between IMA and TG and a significantly negative correlation between IMA and HDL-C implies that IMA can be regarded as a potent risk factor for coronary artery diseases in obese subjects. Indeed, Kazanis et al. [31] showed that serum IMA may provide earlier information of coronary artery disease presence than hsCRP or natriuretic peptide (NT-proBNP) elevation, thus contributing to a more early 
assessment of the overall patient risk. Also, Duarte et al. [11] observed significantly positive correlations between IMA and TC, IMA and LDL-C, IMA and oxidized LDL antibodies, and IMA and hsCRP levels in subjects with hypercholesterolemia, which is in agreement with our findings.

On the other hand, the glucose level was significantly positively correlated with BMI and waist circumference in the control group, but not in the obese group. Also, TC, TG, and LDL-C levels were positively correlated, whereas HDL-C was negatively correlated with BMI and waist circumference in the control group. However, in the obese group only TG was positively correlated with BMI and waist circumference; the other lipid parameters did not show any correlations with BMI and waist circumference. Since lipid parameters and glucose levels of the obese group were higher than those of the control group, these correlations are unexpected findings the underlying mechanism of which needs to be elucidated.

We could not find any other study investigating correlations between serum IMA and hsCRP, TAS or TOS levels in obese people which could be compared with our results. However, Kazanis et al. [16] reported that among overweight/obese postmenopausal women IMA levels were positively and significantly associated with hsCRP. Also, Hartwich et al. [32] found a significantly positive correlation between hsCRP and IMA levels in obese men. They have reported that hsCRP and the cobalt-albumin binding score may serve as potential markers of oxidative stress in obesity and may be useful for selecting patients who are candidates for supplementation with antioxidant vitamins. Since antioxidant-rich diet has been proven to play a role in redox state and atherogenesis at early stage [18], the supplementation of selective and effective antioxidants and antiinflammatory agents to obese subjects might be helpful in reducing the risk of morbidity and mortality from obesity and obesity-related diseases.

One of the limitations of our study was the presence of mild dyslipidemia and mild hyperglycemia in some subjects, a situation which is generally seen in obese subjects and cannot be completely avoided.

In conclusion, our results demonstrated that increased oxidative stress and inflammation and decreased antioxidative defense are present in obese subjects. Those alterations resulted in increased levels of IMA which is a marker of ischemia. Also, obesity and insulin were found to be independent determinants of IMA. Thus, obese subjects are under a high risk of ischemia, and IMA may be used as a biomarker of oxidative stress and ischemia in these subjects. However, further larger clinical studies and laboratory investigations are required to confirm the role of IMA as a potential marker of oxidative stress and ischemia and to explore the association between IMA and insulin levels.

\section{Acknowledgments}

The authors thank Assist. Prof. Dr. Yasemin Durduran for her assistance in the statistical analysis.

\section{Disclosure Statement}

There were no conflict of interest to declare. 


\section{References}

1 WHO Obesity: Preventing and Managing the Global Epidemic. Report of a WHO Consultation. Geneva, 3-5 June 1997. WHO Technical Report Series number 894, WHO, Geneva, 2000.

- 2 Haslam DW, James WP: Obesity. Lancet 2005;366:1197-1209.

- 3 Antuna-Puente B, Feve B, Fellahi S, Bastard JP: Adipokines: the missing link between insulin resistance and obesity. Diabetes Metab 2008;34:2-11.

4 Calle EE, Rodriguez C, Walker-Thurmond K, Thun MJ: Overweight, obesity, and mortality from cancer in a prospectively studied cohort of U.S. adults. N Engl J Med 2003;348:1625-1638.

- 5 Higdon JV, Frei B: Obesity and oxidative stress. A direct link to CVD? Arterioscler Thromb Vasc Biol 2003; 23:365-367.

- 6 Chan B, Dodsworth N, Woodrow J, Tucker A, Harris R: Site-specific N-terminal auto-degradation of human serum albumin. Eur J Biochem 1995;227:524-528.

- 7 Roy D, Quiles J, Gaze DC, Collinson P, Kaski JC, Baxter GF: Role of reactive oxygen species on the formation of the novel diagnostic marker ischemia modified albumin. Heart 2006;92:113-114.

- 8 Peacock F, Morris DL, Anwaruddin S, Christenson RH, Collinson PO, Goodacre SW, Januzzi JL, Jesse RL, Kaski JC, Kontos MC, Lefevre G, Mutrie D, Sinha MK, Uettwiller-Geiger D, Pollack CV: Meta-analysis of ischemia- modified albumin to rule out acute coronary syndromes in the emergency department. Am Heart J 2006;152:253-262.

9 Bar-Or D, Lau E, Winkler JV: A novel assay for cobalt-albumin binding and its potential as a marker for myocardial ischemia-a preliminary report. J Emerg Med 2000;19:311-315.

-10 Valle Gottlieb MG, da Cruz IB, Duarte MM, Moresco RN, Wiehe M, Schwanke CH, Bodanese LC: Associations among metabolic syndrome, ischemia, inflammatory, oxidatives, and lipids biomarkers. J Clin Endocrinol Metab 2010;95:586-591.

-11 Duarte MM, Rocha JB, Moresco RN, Duarte T, Da Cruz IB, Loro VL, Schetinger MR: Association between ischemia-modified albumin, lipids and inflammation biomarkers in patients with hypercholesterolemia. Clin Biochem 2009;42:666-671.

-12 Piwowar A, Knapik-Kordecka M, Warwas M: Ischemia-modified albumin level in type 2 diabetes mellitus - preliminary report. Dis Markers 2008;24:311-317.

-13 Erel 0: A novel automated direct measurement method for total antioxidant capacity using a new generation, more stable ABTS radical cation. Clin Biochem 2004;37:277-285.

-14 Erel O: A new automated colorimetric method for measuring total oxidant status. Clin Biochem 2005;38: 1103-1111.

15 Piva SJ, Duarte MM, Da Cruz IB, Coelho AC, Moreira AP, Tonello R, Garcia SC, Moresco RN: Ischemia-modified albumin as an oxidative stress biomarker in obesity. Clin Biochem 2011;44:345-347.

-16 Kazanis K, Dalamaga M, Kassi E, Nounopoulos C, Manolis AS, Merantzi G, Jullien G, Dionyssiou-Asteriou A: Serum levels of ischemia modified albumin in overweight/obese postmenopausal women: a potential biomarker of atherosclerotic burden associated with oxidative stress. Maturitas 2011;70:182-187.

17 Victor RG, Kaplan NM. Systemic hypertension: mechanisms and diagnosis; in Zipes DP, Libby P, Bonow RO, Braunwald E (eds): Braunwald's Heart Disease, ed 8. Philadelphia, Elsevier Saunders, 2008, pp 1789-1806.

-18 Hermsdorff HH, Puchau B, Volp AC, Barbosa KB, Bressan J, Zulet MÁ, Martínez JA: Dietary total antioxidant capacity is inversely related to central adiposity as well as to metabolic and oxidative stress markers in healthy young adults. Nutr Metab (Lond) 2011;8:59.

19 Matthews DR, Hosker JP, Rudenski AS, Naylor BA, Treacher DF, Turner RC: Homeostasis model assessment: insulin resistance and beta-cell function from fasting plasma glucose and insulin concentrations in man. Diabetologia 1985;28:412-419.

-20 Hermsdorff HH, Zulet MA, Puchau B, Martínez JA: Central adiposity rather than total adiposity measurements are specifically involved in the inflammatory status from healthy young adults. Inflammation 2011; $34: 161-170$.

-21 Stuart Wood I, de Heredia FP, Wang B, Trayhurn P: Cellular hypoxia and adipose tissue dysfunction in obesity. Proc Nutr Soc 2009;68:370-377.

-22 Tamakoshi K, Yatsuya H, Kondo T, Ishikawa M, Zhang H, Murata C, Otsuka R, Mabuchi T, Hori Y, Zhu S, Yoshida T, Toyoshima H: Long-term body weight variability is associated with elevated C-reactive protein independent of current body mass index among Japanese men. Int J Obes Relat Metab Disord 2003;27: 1059-1065.

-23 Visser M, Bouter LM, McQuillan GM, Wener MH, Harris TB: Elevated C-reactive protein levels in overweight and obese adults. JAMA 1999;282:2131-2135.

-24 Sbarouni E, Georgiadou P, Kremastinos DT, Voudris V: Ischemia modified albumin: is this marker of ischemia ready for prime time use? Hellenic J Cardiol 2008;49:260-266.

-25 Festa A, D'Agostino R Jr, Williams K, Karter AJ, Mayer-Davis EJ, Tracy RP, Haffner SM: The relation of body fat mass and distribution to markers of chronic inflammation. Int J Obes Relat Metab Disord 2001;25:14071415.

26 Santos AC, Lopes C, Guimarães JT, Barros H: Central obesity as a major determinant of increased highsensitivity C-reactive protein in metabolic syndrome. Int J Obes (Lond) 2005;29:1452-1456. 
27 Pou KM, Massaro JM, Hoffmann U, Vasan RS, Maurovich-Horvat P, Larson MG, Keaney JF Jr, Meigs JB, Lipinska I, Kathiresan S, Murabito JM, O’Donnell CJ, Benjamin EJ, Fox CS: Visceral and subcutaneous adipose tissue volumes are cross-sectionally related to markers of inflammation and oxidative stress: the Framingham Heart Study. Circulation 2007;116:1234-1241.

-28 Ahmadi N, Eshaghian S, Huizenga R, Sosnin K, Ebrahimi R, Siegel R: Effects of intense exercise and moderate caloric restriction on cardiovascular risk factors and inflammation. Am J Med 2011;124:978-982.

29 Keaney JF Jr, Larson MG, Vasan RS, Wilson PW, Lipinska I, Corey D, Massaro JM, Sutherland P, Vita JA, Benjamin EJ: Framingham Study. Obesity and systemic oxidative stress: clinical correlates of oxidative stress in the Framingham Study. Arterioscler Thromb Vasc Biol 2003;23:434-439.

-30 Block G, Dietrich M, Norkus EP, Morrow JD, Hudes M, Caan B, Packer L: Factors associated with oxidative stress in human populations. Am J Epidemiol 2002;156:274-285.

-31 Kazanis K, Dalamaga M, Nounopoulos C, Manolis AS, Sakellaris N, Jullien G, Dionyssiou-Asteriou A: Ischemia modified albumin, high-sensitivity C-reactive protein and natriuretic peptide in patients with coronary atherosclerosis. Clin Chim Acta 2009;408:65-69.

-32 Hartwich J, Góralska J, Siedlecka D, Gruca A, Trzos M, Dembinska-Kiec A: Effect of supplementation with vitamin $\mathrm{E}$ and $\mathrm{C}$ on plasma hsCRP level and cobalt-albumin binding score as markers of plasma oxidative stress in obesity. Genes Nutr 2007;2:151-154. 